\title{
Field evaluation of hydrological performance of a bioretention basin in an urban tropical catchment
}

\author{
J. Wang ${ }^{1}$, L. Chua ${ }^{2}$ \& P. Shanahan ${ }^{1}$ \\ ${ }^{I}$ Department of Civil and Environmental Engineering, \\ Massachusetts Institute of Technology, USA \\ ${ }^{2}$ School of Engineering, Faculty of Science Engineering \\ \& Built Environment, Deakin University, Australia
}

\begin{abstract}
Bioretention basins or rain gardens are constructed green infrastructure in developed areas that retain and treat stormwater runoff. This study evaluates whether a tropical basin in Singapore that is built according to design guidelines from temperate countries has sufficient storage and infiltration capacity to handle tropical storms. Flow measurements from 80 storm events which varied in rainfall depth $(2.6-71.8 \mathrm{~mm})$, event duration $(10 \mathrm{~min}-2.8 \mathrm{hr})$, and antecedent dry period (ADP) (0.25-9.08 days) were recorded for half a year. Hydrological performance in terms of surface and subsurface storage for each storm event has been analyzed. Results show that the basin storage capacity is inadequate since in about $50 \%$ of the events, more than $50 \%$ of the runoff overflows the basin without soil treatment. In a storm event, the subsurface storage space remains fully saturated throughout the ponding period and the infiltration rate estimated based on the aggregate statistics of 59 events with extended surface infiltration is $1.7 \mathrm{~cm} / \mathrm{hr}$. This is within the same order of magnitude as that found by direct field measurement using a double-ring infiltrometer $(4.4 \mathrm{~cm} / \mathrm{hr})$ but is lower than a recommended rate of $>10 \mathrm{~cm} / \mathrm{hr}$. The information drawn from this study could be of use to stormwater managers for sustainable planning and development. For instance, this study suggests that in order to meet pollutant removal rate targets, a tropical basin should be sized to retain a critical water quality volume (WQV) in the range of 10 to $30 \mathrm{~mm}$.
\end{abstract}


Keywords: low impact development, best management practices, stormwater management, bioretention basin, rain garden, hydrology, water quality volume, urban catchment, tropics, infiltration.

\section{Introduction}

BMPs (best management practices) are sustainable strategies aimed at reinstating pre-urban development hydrological features including storage, infiltration, runoff, and groundwater recharge through detention and treatment of polluted runoff at its source. BMPs such as bioretention basins and permeable pavement have been shown to be effective in reducing runoff volume (DeBusk and Wynn [1]) and removing pollutants (Glass and Bissouma [2], Marchioni and Becciu [3]) in temperate regions. Studies have been carried out for investigating important field parameters such as saturated hydraulic conductivity $\left(\mathrm{K}_{\mathrm{sat}}\right)$ for basins in tropical and cold climates (FAWB [4], Paus et al. [5]). Both studies recommended a $\mathrm{K}_{\text {sat }}$ value of more than $10 \mathrm{~cm} / \mathrm{hr}$ for cells so as to maintain satisfactory performance. Another important factor that determines performance is the amount of spilled or overflow volume. Becciu and Raimondi [6] have used a probabilistic model to evaluate the ability of detention basins to manage overflows.

However, there are limited hydrological studies based on continuous, high resolution, long-term rainfall and flow records for basins in a tropical urban setting, especially for bioretention basins. The rainfall-runoff characteristics in tropical regions such as Singapore are very different from those in temperate places. For instance, rainfall in the tropics is often of higher intensity, having shorter event duration and antecedent dry period. These climatic differences also suggest that tropical basins may not have sufficient storage and infiltration capacity to handle tropical storms if they have been designed according to temperate design guidelines. In this context, the objective of this study is to assess the hydrological performance of a bioretention basin in the setting of a highly urbanized tropical catchment and to attempt to recommend appropriate sizing guidelines. To investigate the storage capacity, an event-based water balance is computed to compare the fraction of runoff that is able to infiltrate and hence gets treated to the fraction of runoff that overflows the basin without treatment. Additionally, hydrological performance in terms of time evolution of cumulative storage, surface storage, and subsurface storage for each storm event is analyzed statistically. Infiltration rate is also estimated from aggregate statistics as well as from direct field measurement. The field results from this study could be used for validating models such as RECARGA (Dussaillant et al. [7]) for bioretention basins in tropical applications.

\section{Methodology}

\subsection{Site description}

The study site, Balam Estate Rain Garden (Figure 1), which includes $240 \mathrm{~m}^{2}$ of effective treatment area and $760 \mathrm{~m}^{2}$ of landscaped area (Wang et al. [9]), is 
designed to receive stormwater runoff from a highly impervious (about 88\%) residential catchment $\left(16,800 \mathrm{~m}^{2}\right)$, with a time of concentration of about $10 \mathrm{~min}$. The treatment area is partitioned into two above-ground cells that are hydraulically interconnected by ten pipes.

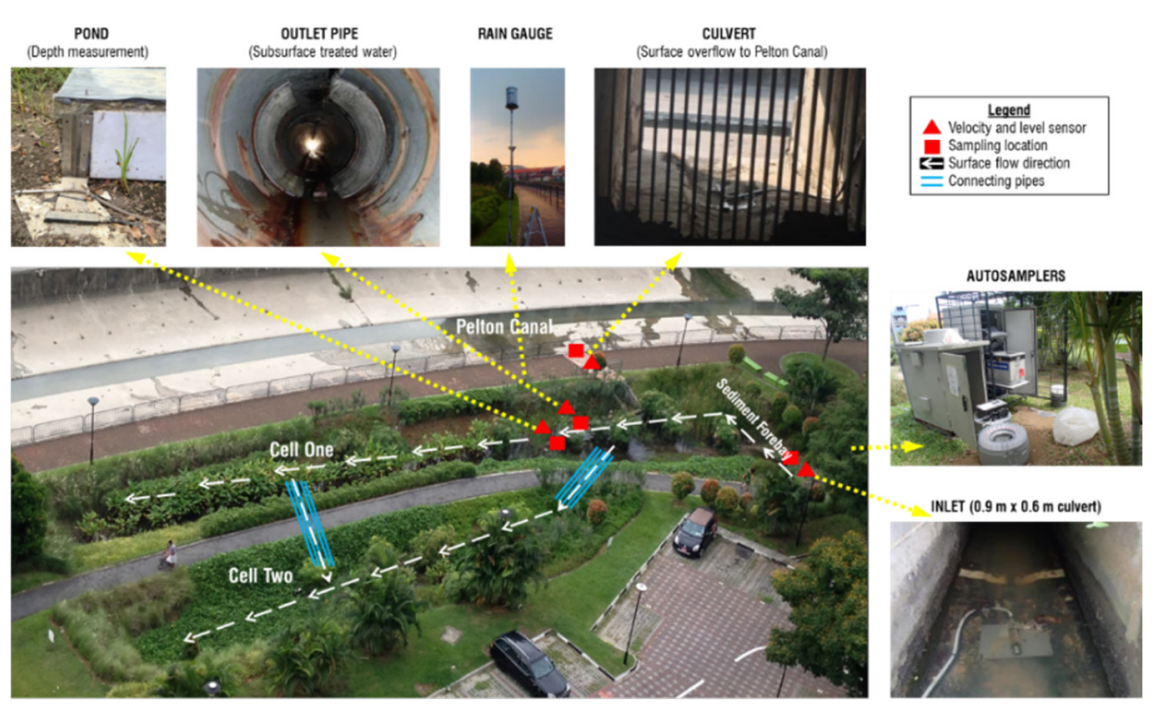

Figure 1: Plan view of Balam Estate Rain Garden showing the on-site instrumentation.

The basin has one entrance (a $0.9 \mathrm{~m}$ high by $0.6 \mathrm{~m}$ wide inlet) and two exits (a culvert for surface overflow and an outlet for subsurface drainage) (Figure 1). The culvert ( $1.1 \mathrm{~m}$ high by $1.2 \mathrm{~m}$ wide) has an overflow weir (about $13.7 \mathrm{~cm}$ above the basin bottom) that limits the amount of surface ponding in the basin by discharging overflow into the neighboring drainage way (Pelton Canal). Two subsurface outlet pits collect runoff treated by soil filtration from underdrains $(10 \mathrm{~cm}$ diameter highdensity polyethylene (HDPE) perforated pipes). The outlet pits then discharge the filtrate into Pelton Canal through a $30 \mathrm{~cm}$ diameter polyvinyl chloride outlet pipe. The soil filter media is underlain by a HDPE liner to prevent exfiltration into the surrounding soil and maintain a $35 \mathrm{~cm}$ thick saturated anoxic zone that is formed by raising the outlet to a $35 \mathrm{~cm}$ higher elevation relative to the underdrains. Nonperforated goose-neck discharge pipes (10 cm diameter) convey the filtrate from the underdrains to the outlet pipe. The subsurface basin treatment area consists of four-layered soil filter media (from surface to bottom): a $40 \mathrm{~cm}$ sandy-loam filter layer; a $10 \mathrm{~cm}$ fine-sand transition layer; a $30 \mathrm{~cm}$ saturated zone of hard rocks (average size of $50 \mathrm{~mm}$ and $65 \%$ by volume) and wood chips (average size of $5 \mathrm{~mm}$ and $35 \%$ by volume); and a $15 \mathrm{~cm}$ drainage layer of fine gravel (average size of 2-5 mm) (Wang et al. [9], Ong et al. [10]). 


\subsection{Data collection}

A real-time monitoring system that consisted of flow and water-level measurement equipment was installed in the Balam Estate Rain Garden from June 2013 to November 2013. Four Doppler ultrasonic area-velocity level sensors (ISCO-2150 Area Velocity Module with 2105 Interface, Teledyne Isco, Lincoln, Nebraska, USA) were used to continuously monitor flow rates at the inlet, outlet, and culvert as well as ponding water level at one-minute intervals. Figure 1 shows the placement of these four sensors at the inlet; at an arm's length into the outlet pipe; downstream of a $10 \mathrm{~cm}$ grated trash trap at the culvert; and on the basin floor. Rainfall intensity ( 1 min interval) was measured with a tipping bucket rain gauge (Model TB4, Hydrological Services PTY Ltd., Liverpool, NSW, Australia) which was installed on the basin edge at $3 \mathrm{~m}$ above ground. In-situ infiltration rate of the soil filter media was measured with a double-ring infiltrometer (IN10-W: 12 and 24 inches diameter and 20 inches height, Turf-Tec International, Tallahassee, Florida, USA) using the constant head $(10 \mathrm{~cm})$ testing method.

\subsection{Data analysis}

Per minute precipitation records from the rain gauge installed at the field site were used to calculate the total rainfall and antecedent dry period (ADP) for each storm event. The rainfall in a particular minute was assigned to an event in progress if it was within six hours from the previous recorded incidence of rainfall. Intermittent light drizzles with a total rainfall amount of less than $2.54 \mathrm{~mm}$ were excluded from the event count (Driscoll et al. [11]).

Equation (1) was used to compute the difference between the total inflow volume and the total outflow volume, which we define as the water balance, WB. When the total inflow exactly equals the total outflow, $\mathrm{WB}=0 \%$.

$$
\mathrm{WB}=\left(\sum V_{\text {out }}-\sum V_{\text {in }}\right) / \sum V_{\text {in }} \times 100 \%
$$

where: $\mathrm{V}_{\text {out }}=\mathrm{V}_{\text {outlet }}+\mathrm{V}_{\text {culvert }}$ and $\mathrm{V}_{\text {in }}=\mathrm{V}_{\text {rain }}+\mathrm{V}_{\text {inlet }}, \mathrm{V}_{\text {in }}$ and $\mathrm{V}_{\text {out }}$ are the total discharge $\left(\mathrm{m}^{3}\right)$ into and out of the basin respectively, $V_{\text {rain }}$ is the direct rainfall onto the basin $\left(\mathrm{m}^{3}\right), \mathrm{V}_{\text {inlet }}\left(\mathrm{m}^{3}\right)$ is the catchment runoff entering the basin, $V_{\text {outlet }}\left(\mathrm{m}^{3}\right)$ is the subsurface water discharge, and $V_{\text {culvert }}\left(\mathrm{m}^{3}\right)$ is the discharge through the overflow culvert that bypasses the basin untreated.

To compute cumulative storage, a mass balance of water into and out of the basin requires the storage rate to be the difference between the inflow and outflow rates in Equation (2).

$$
\left(\mathrm{Q}_{\text {rain }}+\mathrm{Q}_{\text {inlet }}\right)-\left(\mathrm{Q}_{\text {culvert }}+\mathrm{Q}_{\text {outlet }}\right)=\mathrm{Q}_{\text {ponding }}+\mathrm{Q}_{\text {subsurface }}
$$

where $\mathrm{Q}_{\text {ponding }}$ and $\mathrm{Q}_{\text {subsurface }}$ are the surface storage rate $(\mathrm{L} / \mathrm{s})$ and subsurface storage rate $(\mathrm{L} / \mathrm{s})$ respectively, $\mathrm{Q}_{\text {rain }}$ is the direct rainfall onto the basin $(\mathrm{L} / \mathrm{s}), \mathrm{Q}_{\text {inlet }}$ $(\mathrm{L} / \mathrm{s})$ is the catchment runoff entering the basin, $\mathrm{Q}_{\text {outlet }}(\mathrm{L} / \mathrm{s})$ is the subsurface water discharge rate, and $\mathrm{Q}_{\text {culvert }}(\mathrm{L} / \mathrm{s})$ is the discharge rate through the overflow culvert that bypasses the basin untreated. Cumulative storage is the storage rate accumulated over time. To compute surface ponding, the basin horizontal cross- 
sectional area at different elevations was computed from as-built drawings for the basin. From these, volume-area-stage curves were computed.

\section{Results and discussion}

\subsection{Water balance and water quality volume (WQV)}

An event-based water balance was computed according to Equation (1). Figure 2 (a) is a histogram showing the range of water balance over 80 events $(-75 \%$ to $118 \%$ with a root mean square error (RMSE) of $34 \%$ ). Events with a water balance of $29 \%$ to $-39 \%$ are within one standard deviation of the mean.

Figure 2(b) shows plots of water balance as a function of rainfall depth and ADP. There is no obvious trend in how either factor separately affects the water balance because the water balance is affected by both rainfall depth and ADP combined. However, some explanations for the poor water balance seen in large events can be offered. In large events, direct runoff from adjacent landscaped area is not accounted in the measured inflow. There is also on occasion backflow of water from the bordering Pelton Canal into the outlet and culvert, hence affecting the water balance. This phenomenon is observed in 11 events (Figure 2(b)). Errors in field measurements due to blockage of sensors by floating objects like fallen leaves and trash especially at the culvert trash grate that is located upstream of the culvert sensor could be another source of error. However, weekly cleaning of the basin was carried out to minimize such instances. In addition, the length of ADP affects the water balance because it determines the degree of initial soil moisture in the unsaturated filter media layer at the start of an event. Hence, the available subsurface storage capacity for retention of infiltrated water varies from event to event. For events with very short ADP, there is also a possibility that the next event arrives before the ponded water from the prior event is able to infiltrate completely. This phenomenon is observed in three events with ADPs of 0.42, 0.79, and 1.25 days.

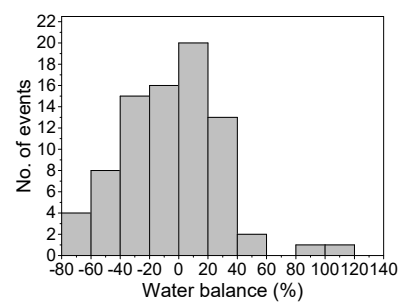

(a)

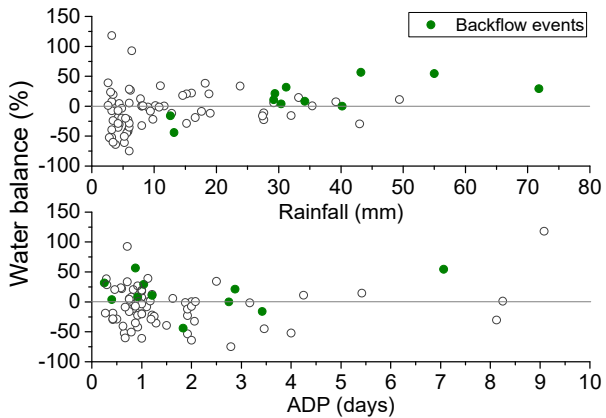

(b)

Figure 2: (a) A histogram showing water balance for 80 events. (b) Plots of water balance against rainfall depth $(\mathrm{mm})$ and $\mathrm{ADP}$ (days) for 80 events. 
Figure 3 plots the percentage of total inflow volume that exits the basin as surface overflow (via the culvert) as compared to subsurface flow (via the outlet). Due to the complications in the water balance computation, six events with poor water balance (water balance ranging from $29 \%$ to $57 \%$ ) are excluded from the computation of the culvert fraction and two events (water balance of $93 \%$ and $118 \%$ ) are excluded from the outlet fraction computation. As the outlet and culvert are the only two exits from the basin, the two figures would add up to $100 \%$ if there was a perfect water balance for each event.

(a)

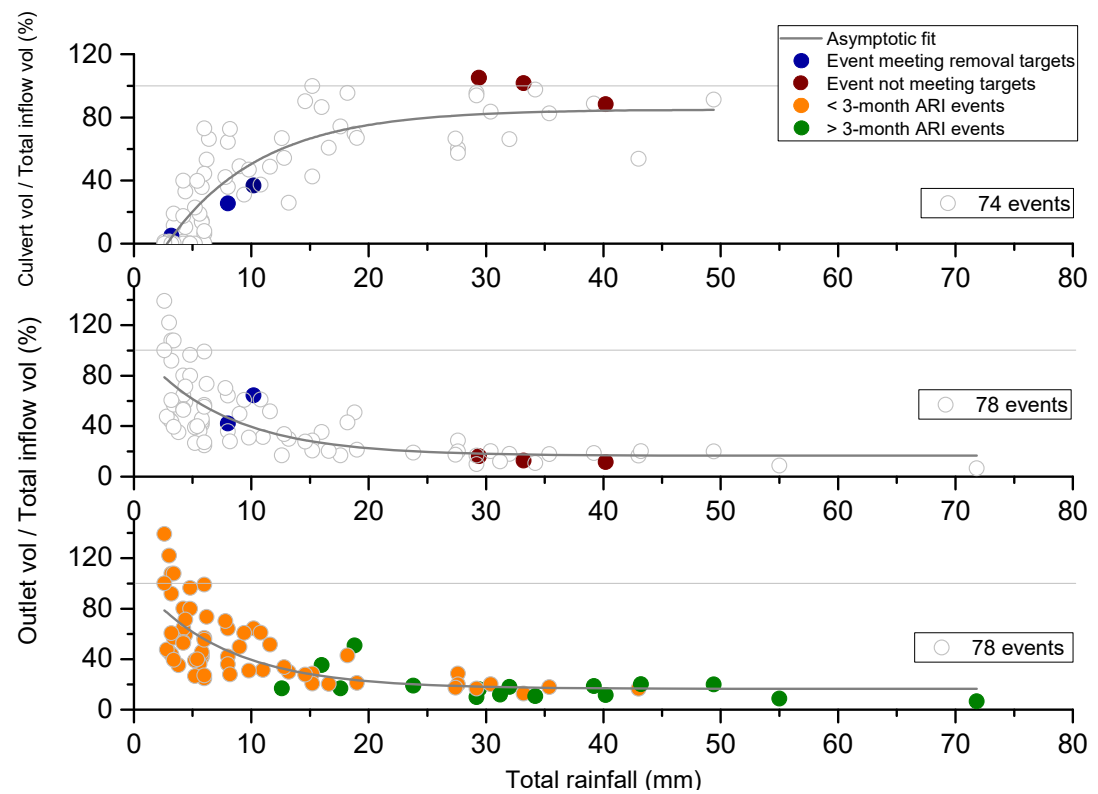

Figure 3: Percentage of (a) culvert discharge volume and (b) outlet discharge volume over total inflow volume with water quality performance for selected sampled events; (c) percentage of outlet discharge volume over inflow volume with events separated into $>$ and $<3$ month ARI categories.

Figure 3 shows that as rainfall depth increases, there is an exponential increase in the percentage of runoff exiting through the culvert without receiving soil treatment (Figure 3(a)) and a corresponding exponential decrease in the percentage of runoff receiving soil treatment by exiting through the outlet (Figure 3(b)). These asymptotic trends reflect the tendency of additional inflow to route through the culvert rather than the subsurface soil filter and outlet. This is expected because in a large event, as the available subsurface space is filled up and the soil filter media becomes saturated, a larger proportion of any additional inflow would have to exit through the culvert instead of the outlet. The limit in the subsurface flow is also reflected in the asymptotes seen in Figure 3(b) and 3(c) in which the outlet fraction 
continues to diminish but at a slower pace when rainfall depth increases beyond the $30 \mathrm{~mm}$ mark.

Results from Wang et al. [8] for six events during which water quality was analyzed show that events with a higher outlet fraction are able to meet the pollutant removal rate targets $(80 \%$ removal in total suspended solids, $45 \%$ in total nitrogen, and $45 \%$ in total phosphorus, (PUB [12])) while events with a lower outlet fraction fail to meet the removal rate targets (Figure 3(a) and (b)). This is expected since additional removal processes like soil adsorption and plant uptake occur in the subsurface for phosphorus species while biochemical transformations like ammonification, nitrification, and denitrification are carried out by bacteria residing within the soil filter media for nitrogen species. Hence, basin treatment is more efficient when a higher percentage of runoff is retained, infiltrated, and exits through the outlet.

The term "water quality volume" or WQV refers to the runoff volume specified to be captured and treated for adequate basin performance in removing pollutants. Figure 3 shows that in about $50 \%$ of the events, more than $50 \%$ of the runoff overflows the basin via the culvert without soil treatment. For events with $>20$ $\mathrm{mm}$ rainfall depth, less than $30 \%$ of the runoff gets infiltrated, soil-treated, and discharged via the outlet. This reflects the inadequacy of basin storage capacity which compromises the efficiency of basin.

Since out of the six sampled events in the study by Wang et al. [8], the largest event that still exhibits satisfactory pollutant removal rate has a rainfall depth of about $10 \mathrm{~mm}$ while the smallest event not meeting the pollutant removal standards has a rainfall depth of about $30 \mathrm{~mm}$, a suitable WQV will be in the range of 10 to $30 \mathrm{~mm}$. The same conclusion can be drawn from Figure 3(c) which illustrates that the range of 10 to $30 \mathrm{~mm}$ includes both events of higher rainfall intensity (i.e. $>3$ month annual recurrence interval (ARI) events) and events of lower rainfall intensity ( $<3$ month ARI events). The range of $10-30 \mathrm{~mm}$ includes both mild, long-duration events of high total rainfall depth but low rainfall intensity (orange dots in Figure 3(c)) and intense, short-duration events of low rainfall depth but high rainfall intensity (green dots in Figure 3(c)). Therefore, this range span points to where the critical WQV lies but exactly where it is within this range depends on the characteristics of the rainfall event. Hence, a basin designer could be flexible in deciding the appropriate WQV on a case-by-case basis, with $30 \mathrm{~mm}$ being the more conservative estimate and $10 \mathrm{~mm}$ being the more stringent estimate. Moreover, Wang et al. [8] estimated that in order to capture $90 \%$ of the total runoff in the six months of the field monitoring period, a WQV of $32 \mathrm{~mm}$ would be required. This amount corresponds to the conservative estimate of 30 $\mathrm{mm}$ in Figure 3 which marks the beginning of the asymptotes.

\subsection{Surface and subsurface storage}

Equation (2) is used to compute the storage rate which is the difference between the inflow and outflow rates. To partition the amount of water stored between the surface (ponded water) and subsurface (within soil media) compartments over time, the storage rate is cumulated over time to give rise to the cumulative storage term. The surface storage term is found from the pond storage-stage relationship. 
The subsurface storage is found by taking the difference between the cumulative storage and surface storage. Figures 4(a)-(c) illustrate the time evolution of the cumulative storage, surface storage and subsurface storage terms during three events with varying degrees of rainfall depth: a small (Event \#63, $2.6 \mathrm{~mm}$ ), a medium (Event \#61, 8.2 mm), and a large (Event \#47, $29.4 \mathrm{~mm}$ ) event.

(a)

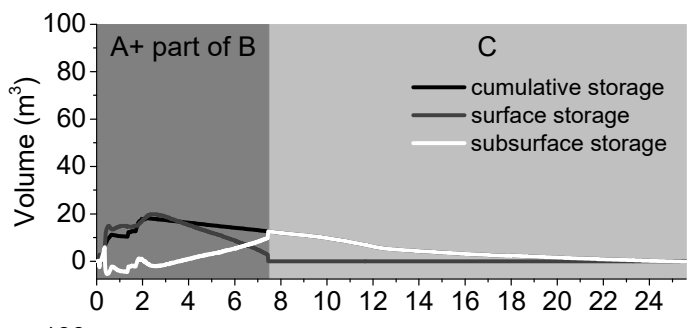

(b)

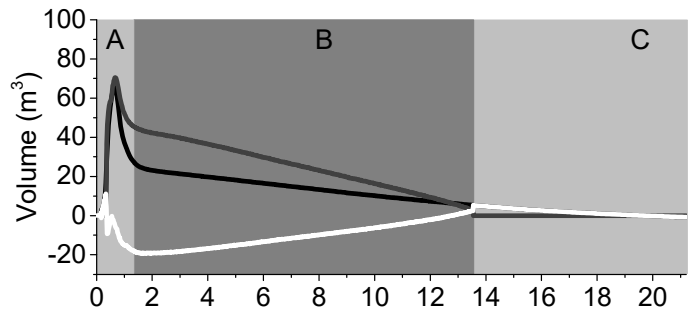

(c)

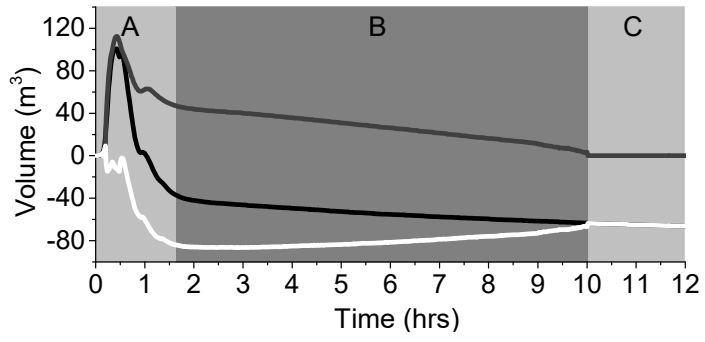

Figure 4: Time series of cumulative storage, surface storage, and subsurface storage for (a) a small event (Event \#63, $2.6 \mathrm{~mm}$ ), (b) a medium event (Event \#61, $8.2 \mathrm{~mm}$ ), and (c) a large event (Event \#47, $29.4 \mathrm{~mm}$ ). Time series are separated into three stages $(\mathrm{A}, \mathrm{B}$, and $\mathrm{C})$.

Figure 4 is analyzed more closely by segregating the time series into three defined stages, A, B and C, which are the three phases in basin drainage. In Stage A, both cumulative storage and surface storage increase sharply due to the high inflow of catchment runoff (inlet) at the start of the event. Once the pond water level exceeds the extended detention depth of $13.7 \mathrm{~cm}$ and surcharges the basin, water overflows and exits the basin through the culvert. High culvert overflow leads to quick recession in cumulative storage and surface storage. Thus, this sharp initial drop reflects the fast drainage from the basin as the culvert is actively channeling away surcharged water. This phenomenon is only seen in events that are sufficiently large to cause a culvert overflow (Figure 4(b) and 4(c)). In small 
events where there is no culvert overflow, inflow is retained entirely within the basin and eventually infiltrated (Figure 4(a)). Thus, there is no significant change in cumulative storage and surface storage. The subsurface storage declines sharply in medium and large events as water is discharged through the outlet. Since the total available pore space in the unsaturated zone is estimated to be about $23.3 \mathrm{~m}^{3}$, the number of times that the unsaturated zone is flushed out can be estimated from the reduction in subsurface storage. For instance, the unsaturated zone is flushed out once during the selected medium event and about four times during the large event in Figure 4(b) and (c).

The start of Stage B corresponds to the time point when pond water level falls below the extended surface detention depth of $13.7 \mathrm{~cm}$ (i.e. culvert overflow just ceased). The end of Stage B corresponds to the termination of ponding in the basin (Figure 4). Therefore, throughout this stage, water infiltrates into the soil under a ponding head. By this stage, inflow has also ceased. For events with multiple rainfall peaks, which might result in multiple instances of pond water level rising above and then falling below the detention depth of $13.7 \mathrm{~cm}$, Stage B is defined as the last instance. This definition facilitates statistical analysis in the next section. However, for a small event, since there is no culvert overflow, there is no distinction between Stage B and Stage A. There are 21 such small events out of the entire 80 events.

Since there is zero culvert overflow in Stage B, Stage B represents a duration when there is slower drainage of ponded water as water infiltrates into the soil media under a ponding head as compared to the faster channeling off via culvert overflow in Stage A. This phenomenon is reflected in the gentler slope of decline of surface storage curve in Stage B compared to Stage A. The gentler decline of surface storage curve reflects the amount of ponded water that is entering the unsaturated soil zone. Moreover, since there is no culvert discharge or inflow during Stage B, the influence of culvert discharge and inflow discharge on the storage term is removed from Equation (2). Hence, the decline in the cumulative storage curve in this stage entirely represents the amount of water leaving the basin through the outlet. Therefore, a decreasing cumulative storage curve decreases subsurface storage since water is flowing out of the basin while a decreasing surface storage curve increases subsurface storage since water is transferred from one storage compartment (the pond) to another compartment (the unsaturated soil zone). The relative slope of cumulative storage compared to that of surface storage determines the net change in the subsurface storage in Stage B. Since the slope of the surface storage curve is steeper than that of the cumulative storage curve, this results in increasing subsurface storage during Stage B (Figure 4). In this stage, more water infiltrates into the soil under a ponding head than exits the basin from the outlet.

The start of Stage $\mathrm{C}$ is marked by zero surface-ponding head until the end of drainage or the start of the next event, whichever comes earlier. Thus, Stage C represents subsurface drainage by gravity from the saturated soil media to an unsaturated state. In this stage, since there is no surface storage, the drainage of water from the basin as represented by the subsurface curve coincides with the cumulative storage curve. 
Figure 5 presents statistics of some observed features. For the 80 events, the average ponding duration (Stage A and B) is 12.5 hours with a standard deviation of 5.5 hours. Out of the 80 events, only 59 events have sufficient rainfall depth to result in culvert overflow and hence a full Stage B, similar to the plots in Figure 4(b) and 4(c). For these 59 events, the start of Stage B that corresponds to zero culvert discharge occurs when the average pond water level is $13.9 \mathrm{~cm}$. This average of $13.9 \mathrm{~cm}$ is not exactly equal to the extended detention depth of $13.7 \mathrm{~cm}$ because accumulating trash at the culvert causes the zero-discharge elevation to vary from event to event. A level of $13.9 \mathrm{~cm}$ corresponds to a surface storage of $40 \mathrm{~m}^{3}$. The average ponding duration in Stage B is 10.1 hours during which about $40 \mathrm{~m}^{3}$ stored in the surface basin needs to infiltrate into the soil. This gives an estimated infiltration rate of $1.7 \mathrm{~cm} / \mathrm{hr}$. This infiltration rate is within the same order of magnitude as the infiltration rate measured in the field using a doublering infiltrometer $(4.4 \mathrm{~cm} / \mathrm{hr})$. However, these fall below the hydraulic conductivity $(>10 \mathrm{~cm} / \mathrm{hr}$ ) recommended for tropical regions by FAWB [4]. In this case, an infiltration rate of $1.7 \mathrm{~cm} / \mathrm{hr}$ under a saturated condition could indicate some degree of surface clogging and soil compaction that could have occurred since the basin was constructed. The average amount of increase in subsurface storage during Stage B is $23.7 \mathrm{~m}^{3}$ which corresponds to about $100 \%$ of the total available porous space (estimated to be about $23.3 \mathrm{~m}^{3}$ ) in the unsaturated zone (Figure 5). This means that the unsaturated zone is likely to stay saturated during ponding in Stage B as the porous volume is fully utilized to store water. However, under the unsaturated condition in Stage $\mathrm{C}$, the average gravity drainage rate is $0.3 \mathrm{~cm} / \mathrm{hr}$ (Figure 5).
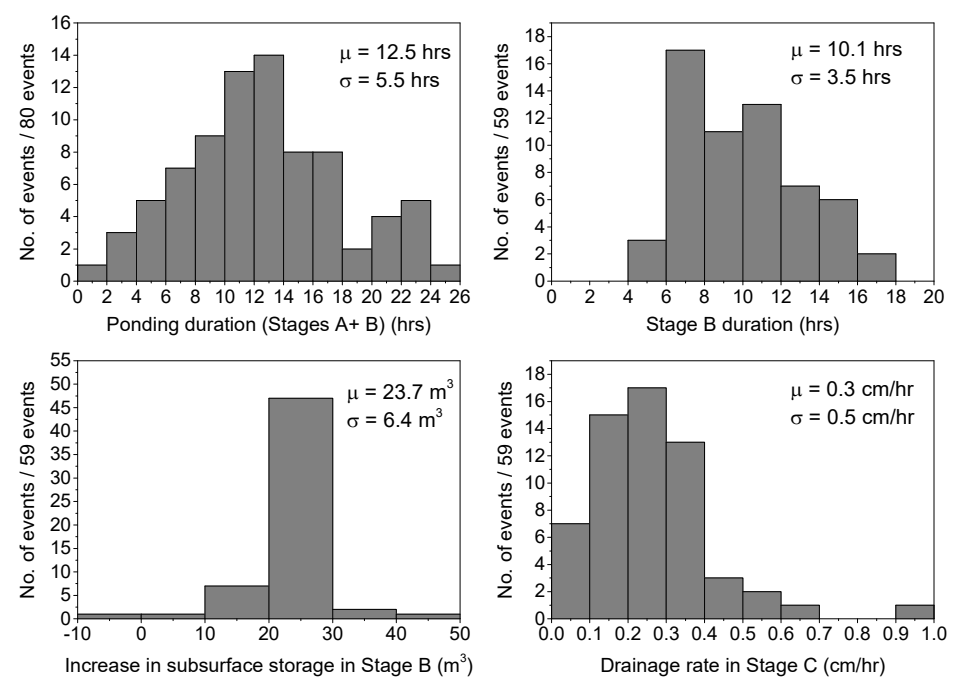

Figure 5: Histograms of ponding duration (of 80 events), Stage B duration (of 59 events), increase in subsurface storage in Stage B (of 59 events), and drainage rate in Stage C (of 59 events). 


\section{Conclusions}

In this study, a six-month field monitoring program has been conducted at a bioretention basin in an urban tropical catchment. Whether this basin has sufficient storage and infiltration capacity to handle tropical storms has been investigated over 80 storm events. The main findings are:

- The basin storage capacity is inadequate since in about $50 \%$ of the events, more than $50 \%$ of the runoff overflows the basin without soil treatment. During events with $>20 \mathrm{~mm}$ of total rainfall depth, less than $30 \%$ of the runoff gets infiltrated and treated in the soil column.

- The information and results drawn from this study could be of use to stormwater managers for sustainable planning and development. For instance, water quality volume (WQV) is an important concept and tool for sizing bioretention basins to ensure that pollutant removal targets are met by retaining a certain amount of runoff. This study suggests that an appropriate WQV for a tropical basin falls in the range of 10 to $30 \mathrm{~mm}$.

- Based on the aggregate statistics of the 59 events with extended surface infiltration, the subsurface soil filter media is found to remain fully saturated under a ponding condition. The infiltration rate is estimated to be $1.7 \mathrm{~cm} / \mathrm{hr}$ which is within the same order of magnitude as that found by direct field measurement using a double-ring infiltrometer $(4.4 \mathrm{~cm} / \mathrm{hr})$. The gravity drainage rate under unsaturated conditions is $0.3 \mathrm{~cm} / \mathrm{hr}$.

- The observed infiltration rate is lower than that intended $(>10 \mathrm{~cm} / \mathrm{hr})$ which indicates some degree of surface clogging and soil compaction after five years of operation. A regular basin maintenance routine could be set up to ensure that the basin maintains an intended infiltration rate.

- $\quad$ Field data, particularly for large storms, showed inconsistencies that made it difficult to close the water balance on all storms. This problem could be at least partially addressed in future monitoring programs by installing more instrumentation and collecting redundant flow measurements.

\section{Acknowledgements}

This research was funded by the National Research Foundation (NRF), Prime Minister's Office, Singapore under its Campus for Research Excellence and Technological Enterprise (CREATE), through the Singapore MIT Alliance for Research and Technology's Center for Environmental Sensing and Modeling (CENSAM) research program. The authors would also like to thank the following for their insightful discussions and field support: Alwi Alkaff, Maria Stefanie Suryadharma, Ong Geok Suat, Yau Wing Ken, Veera Sekaran, and Adeline Wong. 


\section{References}

[1] DeBusk, K. M. and Wynn, T. M. Storm-water bioretention for runoff quality and quantity mitigation. Journal of Environmental Engineering, 137(9), 800-808, 2011.

[2] Glass, C. and Bissouma, S. Evaluation of a parking lot bioretention cell for removal of storm water pollutants. Ecosystems and Sustainable Development V, WIT, Southampton, U.K., 699-708, 2005.

[3] Marchioni, M. and Becciu, G. Experimental results on permeable pavements in urban areas: a synthetic review. International Journal of Sustainable Development and Planning, 10(6), 806-817, 2015.

[4] FAWB. Adoption Guidelines for Stormwater Biofiltration Systems. ISBN 978-0-9805831-1-3. Facility for Advancing Water Biofiltration, Monash University, Melbourne, Australia, 2009.

[5] Paus, K. H., Muthanna, T. M. and Braskerud, B. C. The hydrological performance of bioretention cells in regions with cold climates: seasonal variation and implications for design. Hydrology Research, in press, 2015.

[6] Becciu, G. and Raimondi, A. Probabilistic modeling of the efficiency of a stormwater detention facility. International Journal of Sustainable Development and Planning, 10(6), 795-805, 2015.

[7] Dussaillant, A. R., Cozzetto, K., Brander, K. and Potter, K. W. Green-Ampt model of a rain garden and comparison to Richard's equation model. Sustainable Planning and Development, The Sustainable World, WIT, Southampton, U.K., 891-900, 2003.

[8] Wang, J., Chua, L. and Shanahan, P. Field evaluation of water quality performance of a bioretention basin in an urban tropical catchment. In preparation, 2016.

[9] Wang, J., Wong, T. H. F. and Ong, G. S. Design, construction and monitoring Singapore's first bioretention systems. 6th International Water Sensitive Urban Design Conference, May 5-8, Perth, Australia, 2009.

[10] Ong, G. S., Kalyanaraman, G., Wong, K. L. and Wong, T. Monitoring Singapore's first bioretention system: rain garden at Balam Estate. 7th International Conference on Water Sensitive Urban Design, Melbourne Cricket Ground, Melbourne, Australia, 2012.

[11] Driscoll, E., Palhegyi, G., Strecker, E. and Shelley, P. Analysis of storm event characteristics for selected rainfall gages throughout the United States. Report No. EPA-800-D-89-001. U.S. Environmental Protection Agency, Washington, D.C., USA, 1989.

[12] PUB. Chapter 7, Bioretention basins. In: Engineering Procedures for ABC Waters Design Features. Public Utilities Board of Singapore, 2014. www.pub.gov.sg/abcwaters/abcwatersdesignguidelines/documents/ bioretention_basins.pdf 